\author{
ARTIGO \\ do/ https://doi.org/10.22481/rpe.v16i43.6316
}

\title{
(RE)PENSANDO AS VEREDAS DA ESCOLA: UM ESTUDO SOBRE A PRÁTICA DAS PROFESSORAS NAS CLASSES MULTIANOS EM PAU DOS FERROS (RN)
}

\author{
(RE)THINKING THE PATHS OF SCHOOL: A STUDY ON THE PRACTICE OF \\ TEACHERS IN MULTI-YEARS CLASSROOMS IN PAU DOS FERROS (RN)
}

\section{(RE)PENSANDO LAS VEREDAS DE LA ESCUELA: ESTUDIO SOBRE LA PRÁCTICA DE PROFESORES EN CLASES MULTIANOS EN PAU DOS FERROS (RN)}

\author{
Geralda Maria de Bem \\ Secretaria Municipal de Educação de Pau dos Ferros - Brasil
}

Cícero Nilton Moreira da Silva

Universidade do Estado do Rio Grande do Norte - Brasil

\begin{abstract}
Resumo: Este texto se organiza a partir de um recorte da dissertação de mestrado intitulada: "A prática docente na Educação do Campo: um estudo em classes multianos de Pau dos Ferros - RN", e tem o objetivo de refletirmos sobre a prática pedagógica das professoras das classes multianos de Pau dos Ferros/RN. A investigação partiu da seguinte questão de estudo: de que modo os professores desenvolvem suas práticas pedagógicas, considerando as especificidades das classes multianos? Assim, adotamos como abordagem metodológica a concepção da pesquisa qualitativa - as discussões e os encaminhamentos tiveram sua ancoragem teórica nas pesquisas de Rocha (2013), Crepaldi (2006), Caldart (2004, 2011), Tardif (2002), entre outros teóricos que discutem a temática em estudo. Em síntese, através das observações da prática docente, como também dos relatos das educadoras acerca do ensino nas classes multianos, pudemos perceber um bom relacionamento entre professor e aluno, bem como aluno-aluno; demostrando, assim, formas significativas de aprendizagem a partir da interação nos trabalhos em grupos, como também no momento do intervalo e nas brincadeiras livres, no contexto escolar.
\end{abstract}

Palavras-chave: Educação do Campo, prática pedagógica, classes multianos.

\begin{abstract}
This text is organized as a cut from the master 's dissertation, entitled: The teaching practice in the Field of Education: a study in multi-years classerooms in Pau dos Ferros city - RN, with the purpose of reflect on pedagogical practice of the teachers of the multi-years classes in Pau dos Ferros / RN. The research started from the following matter of study: how did the teachers develop their practices, considering the multi-years classrooms particularities? It was adopted as methodological approach the conception of qualitative research - the discussions and procedures about the methodological proposal of research was based in the research of Rocha (2013), Crepaldi (2006), Caldart (2004, 2011), Tardif (2002), among other theorists who discuss the thematic at issue. In summary, through observations of teaching practice, as well as the reports of the educators about teaching in the multi-years classrooms, we could see a good relationship between teacher and student,
\end{abstract}


as well as student-student; demonstrating, so, meaningful forms of learning from interaction in group work, but also during the break and in free play, in the school context.

Keywords: Field of Education, pedagogical practice, multi-years classerooms.

Resumen: Este texto está organizado a partir de un extracto de la tesis de maestria titulado: "Práctica docente en Educación Rural: un estudio en clases multianos en Pau dos Ferros - RN", y tiene el objetivo de reflexionar sobre la práctica pedagógica de los docentes de clases multianos en Pau dos Ferros / RN. La investigación partió de la siguiente pregunta de estudio: ¿Cómo desarrollan los docentes sus prácticas pedagógicas, considerando las especificidades de las clases multianos? Así, adoptamos como enfoque metodológico la concepción de la investigación cualitativa - las discusiones y los referencias tuvieron su anclaje teórico en las investigaciones de Rocha (2013), Crepaldi (2006), Caldart (2004, 2011), Tardif (2002), entre otros teóricos que discuten el tema en estudio. En resumen, a través de las observaciones de la práctica docente, así como de los informes de los educadores sobre la docencia en las clases multianos, pudimos percibir una buena relación entre docente y alumno, así como alumno-alumno; demostrando así formas significativas de aprendizaje a partir de la interacción en el trabajo en grupo, así como en el momento del receso y juego libre, en el contexto escolar.

Palabras-clave: Educación del campo, práctica pedagógica, clases multianos.

\section{Introdução}

Ao abordarmos a Educação do Campo, tratamos especificamente de uma educação destinada aos sujeitos que habitam no campo. Compreendemos que o campo é um espaço onde vivem diferentes sujeitos, no qual existem diferenças singulares entre esses sujeitos e, em alguns casos, com multiplicidades de gênero, etnia, religião, sexo. São, portanto, grupos que estão concentrados num determinado território geográfico, com diferentes visões de mundo, e que podem ser educados de acordo com as suas particularidades. Para isso, deve-se levar em consideração a sua história e sua a cultura.

De acordo com Caldart (2011, p. 153), "não há como educar verdadeiramente o povo do campo sem transformar as condições atuais de sua desumanização". É preciso que os sujeitos sejam mobilizados a participar dos movimentos das lutas sociais, tendo por base, $a$ priori, a educação. Por meio desta, é possível educar e reeducar os sujeitos que vivem no campo, levando em consideração, evidentemente, os seus saberes. A escola pode e deve ser um lugar que valorize a cultura desses sujeitos e que mantenha viva a sua história.

Este artigo foi sistematizado a partir do quarto capítulo da dissertação de mestrado intitulada: “A prática docente na Educação do Campo: um estudo em classes multianos de Pau dos Ferros - RN”, do Curso de Mestrado Acadêmico em Ensino, da Universidade do 
Estado do Rio Grande do Norte (UERN). No referido capítulo, objetivamos analisar a prática pedagógica das professoras das classes multianos de Pau dos Ferros/RN.

Trata-se, portanto, dos dados e dos resultados obtidos por intermédio da realização da pesquisa empírica, realizada nas quatro escolas do referido município. Fizeram parte dessa pesquisa quatro professoras das turmas multianos, uma supervisora e uma gestora escolar. A investigação partiu da seguinte questão: de que modo os professores desenvolvem suas práticas, considerando as especificidades das classes multianos?

Assim, adotamos como abordagem metodológica a concepção da pesquisa qualitativa e fundamentamo-nos em Flick (2009, p. 23), que afirma:

\begin{abstract}
Os aspectos essenciais da pesquisa qualitativa consistem na escolha adequada de métodos e teorias convenientes; no reconhecimento e na análise de diferentes perspectivas; nas reflexões dos pesquisadores a respeito de suas pesquisas como parte do processo de produção de conhecimento; e na variedade de abordagens e métodos.
\end{abstract}

Nesse sentido, no processo de construção da pesquisa, utilizamos alguns dos instrumentos investigativos inerentes à pesquisa qualitativa para a construção dos dados, tais como: observação em sala de aula, análise documental e entrevista semiestruturada. Desse modo, as discussões e encaminhamentos acerca da proposta tiveram sua ancoragem teórica nos pressupostos de Rocha (2013), Caldart (2004), Barros e Moura (2010), Tardif (2002), Oliveira (2002), Flick (2009), entre outros que tratam da temática em estudo.

A observação foi realizada em quatro escolas municipais do campo com turmas multianos, localizadas na zona rural do município de Pau dos Ferros (RN): (1) Unidade de Ensino XII Narcísia Amélia do Nascimento, no Sítio Tapera, a 6 km da zona urbana; (2) Unidade de Ensino VIII José Alves Pereira, no Sítio Raiz, a 10 km; (3) Unidade de Ensino XVIII Manoel Chagas de Aquino, no Sítio Sorriso, a 14 km; e (4) Unidade de Ensino V Francelino Granjeiro, no Sítio Conceição, a 14 km.

Constatamos que cada turma conta com uma professora para lecionar da pré-escola ao $5^{\circ}$ ano do Ensino Fundamental. Em algumas turmas, existe a presença de crianças de creche, e outras com jovens e adultos da Educação de Jovens e Adultos (EJA) - modalidade ofertada com a formação de uma turma na Unidade de Ensino Narcísia Amélia do Nascimento, desde 2015. Essas escolas funcionam em um só turno, o matutino, no horário de 7h às $11 \mathrm{~h} 30$ min, sendo que cada unidade escolar possui apenas uma turma multiano, cuja equipe de trabalho é composta pela professora e um funcionário responsável pela higiene da escola e pela preparação dos alimentos das crianças. Para conhecer e entender como se dá a ação docente 
na sala de aula, foi necessário o levantamento dos dados, por meio de entrevistas e observação de campo. A pesquisa empírica foi realizada nas escolas do campo com turmas multianos do Ensino Fundamental, do município de Pau dos Ferros/RN, pelo fato de serem essas escolas as únicas que ofertam as classes multianos.

Visando a organização dos dados, preservamos a identidade dos entrevistados, apresento-os através de códigos, como: P1 (professora da turma um); P2 (professora da turma dois); P3 (professora da turma três); e P4 (professora da turma quatro); GE (gestora escolar municipal); SE (supervisora escolar municipal). Estas duas últimas são lotadas na Secretaria de Educação do Município, e só eventualmente visitam essas unidades de ensino. Essas escolas não seguem uma filosofia de educação do campo, pois os planejamentos de ensino não se diferenciam daqueles executados nas escolas da zona urbana.

$\mathrm{Na}$ verdade, as ações são realizadas quinzenalmente, tendo como partícipes apenas as quatro professoras do campo que atuam em cada unidade escolar em turmas multianos. Assim, ao realizarmos esse trabalho, contamos com a contribuição das conversas informais, as observações e entrevistas que realizamos com os sujeitos partícipes da pesquisa, as quais contribuíram na análise da prática docente das professoras investigadas (em sua atuação) em cada comunidade escolar.

O primeiro tópico desse trabalho descreve o espaço escolar da sala de aula, local onde a maior parte da pesquisa foi realizada, já que é preciso entender como se desenvolve o trabalho docente diante do contexto das turmas multianos. No segundo segmento, apresentaremos o roteiro das entrevistas e da observação realizadas com as quatro professoras, bem como com a gestora e a supervisora escolar. Constam, ainda, reflexões a respeito da pesquisa documental realizada nas escolas, que nos exigiu um olhar específico para que os dados pudessem ser analisados; e finalizamos nosso trabalho com as considerações finais.

\section{Observação sistematizada do ambiente escolar: a rotina nas salas de aula multianos}

Durante as observações nas referidas escolas, notamos certo clima de interação entre as professoras e os alunos, bem como junto a algumas famílias, que dialogavam sobre seus filhos na hora da chegada ou, muitas vezes, na hora da saída. Essa parceria é fundamental na aprendizagem dos alunos, pois o diálogo contribui para que as famílias ajudem seus filhos a terem interesse em estudar. Tal parceria também facilita o trabalho docente, pois as professoras que lecionam nessas escolas precisam considerar as especificidades dos alunos, suas experiências de vida e seu saber. Como pontuou Freire (2009), a escola deve aproveitar 
os saberes dos educandos para discutir a realidade concreta e associar a disciplina cujo conteúdo se ensina.

Diante desse contexto, os conteúdos trabalhados nas escolas devem respeitar as particularidades dos sujeitos em seus espaços escolares. Na sala de aula de algumas escolas, percebemos que existe um diálogo entre os sujeitos, os quais interagem com a professora, no decorrer das atividades - alunos e professores dialogam entre si. Porém, pelo que pudemos constatar, em outras escolas, os alunos não têm muitas oportunidades para o diálogo, pois a prática escolar centralizou-se no ensino a partir da memorização.

$\mathrm{Na}$ realização das atividades, a professora exigia que os alunos repetissem exercícios através de cópias das palavras ditadas e procurassem responder as questões propostas no livro didático. No que se refere a essa prática, salienta Freire (1996, p. 23): "ensinar não é transferir conhecimentos, conteúdos nem formar é ação pela qual um sujeito criador dá forma, estilo ou alma a um corpo indeciso e acomodado". Assim sendo, é preciso que o professor, ao adentrar na sala de aula, tenha feito uma reflexão sobre sua prática docente, colocando-se aberto às indagações e à curiosidade dos educandos. Segundo Ludke e André (1986, p. 25), "planejar a observação significa determinar com antecedência 'o que' e o 'como' observar. A primeira tarefa, pois, no preparo das observações é a delimitação do objeto de estudo".

No que diz respeito à observação, devemos ressaltar que esse instrumento foi uma das primeiras técnicas da pesquisa qualitativa que compôs a construção dos dados desta pesquisa. Destarte, a observação nas salas de aulas nos proporcionou uma compreensão acerca da prática docente, sobretudo no que se refere às metodologias trabalhadas pelas professoras no dia a dia das escolas, tais como: aula expositiva; trabalho em grupo; oficinas de leitura e oficinas de jogos. Desse modo, a partir do que assevera Libâneo (2008, p. 150), “o professor, ao dirigir e estimular o processo de ensino em função da aprendizagem dos alunos, utiliza intencionalmente um conjunto de ações, passos, condições externas e procedimentos, a que chamamos métodos de ensino".

O processo de observação ocorreu tanto na sala de aula quanto nos espaços externos, no momento dos intervalos, ocasião em que as crianças brincavam, interagindo uns com os outros, num clima agradável, correndo ao ar livre. Em uma das escolas, pensando no contexto em que estão inseridas, os alunos brincavam embaixo das árvores, divertindo-se com os animais, como por exemplo: os passarinhos que faziam ninhos na árvore, os maribondos.

Diante dessas observações, nos espelhamos em Rocha (2013, p. 10), que sintetiza: "nas brincadeiras, as crianças estão nos rios, lidando com a terra, subindo em árvores, 
correndo com os animais, lidando com ferramentas, pessoas e situações que estão a sua volta". Essas brincadeiras ocorriam sob o olhar da professora, que não intervinha na socialização dos alunos, mas os observava, percebendo como era o comportamento de todos. Segundo relatou a professora P1, ela costumava ficar observando-os, no momento do intervalo, porque tinha cuidado para que não viessem ocorrer brigas entre eles. Ela ressalta que, apesar de serem unidos, era preciso observar. Nesse sentido, após o término do intervalo, ao adentrar na sala de aula, a professora conversava sobre o respeito que os alunos deveriam ter com os colegas durante o intervalo.

Esse momento de observação nos fez refletir sobre o conhecimento que essas crianças adquirem em sua vivência, o qual precisa ser trabalhado na sala de aula, no sentido de fazer uma relação com os conhecimentos formais adquiridos na escola. Segundo Madalena Freire (2007), cabe ao professor trabalhar a partir da realidade dos alunos, pois estes, antes de ingressarem na sala de aula, já fazem várias leituras do mundo que os rodeia. Como se sabe, além do conhecimento formal, as brincadeiras são uma forma de aprendizado e as crianças, desde os anos inicias, já exercitam o aprendizado coletivo nas escolas. Segundo Wajskop (2012, p. 35), “a brincadeira é o resultado de relações inter-individuais, portanto, de cultura. A brincadeira pressupõe uma aprendizagem social. Aprende-se a brincar".

Desse modo, as brincadeiras representam uma forma peculiar das crianças expressarem-se e interagirem com outras pessoas. Conforme Angotti (2006, p. 106), "o direito de brincar se apresenta como um dos direitos da cidadania, da mesma forma que o direito à cultura, à arte, ao esporte e ao lazer".

Diariamente, cada professora iniciava a aula com o momento de rotina: acolhida, que é feita com a oração do dia, voltada para o catolicismo, independentemente de haver ou não criança com religião diversa, a oração segue a mesma para todos; em seguida, as professoras seguem cantando uma música em que todos se abraçam, demostrando afetividade e respeito entre si. A música, no início da aula, tem o intuito de possibilitar a socialização entre os alunos. Também é realizado o procedimento de leitura, que tem como intenção proporcionar o ato de leitura de forma prazerosa, isto é, sem requerer do aluno a realização de uma atividade a ela relacionada. Portanto, nas aulas, o ato de leitura faz com que os alunos agucem sua imaginação e curiosidade; permite que os mesmos compreendam que a leitura requer uma gama de finalidades, e uma delas é ler por prazer, ou seja, ler para divertir-se.

Quanto à metodologia trabalhada nas aulas, presenciamos como as professoras trabalham os conteúdos. Algumas iniciam as atividades do dia com dinâmicas e brincadeiras; 
outras iniciam com as atividades de rotinas e, logo após, a leitura; utilizam também o quadro, que é assim dividido: na primeira parte destacam-se as atividades para $1^{\circ}, 2^{\circ}$ e $3^{\circ}$ ano; na segunda parte às relacionadas ao $4^{\circ}$ ano; e em outra parte às destinadas ao $5^{\circ}$ ano. No geral, as atividades propostas são as que constam nos livros didáticos.

Mediante às observações realizadas, a prática dessas educadoras apresenta características predominantemente diferenciadas, pois cada professora desenvolve uma metodologia específica, de acordo com a realidade do contexto escolar. Há aquelas aulas em que o aluno escuta e não questiona. Por outro lado, também há aulas em que o aluno, constantemente, interroga a professora e dialoga sobre o conteúdo que está sendo abordado. Exemplo disso ocorreu nos momentos de leitura - houve uma explanação da professora e, em seguida, os alunos comentavam e interpretavam a leitura de modo coletivo e interativo.

A professora P4 inicia a aula através de dinâmica do aquecimento, em que todos os alunos, de pé e dispostos em círculo, realizam movimentos corporais; em seguida, a professora canta uma música, dando as boas-vindas a todos(as); depois brincam de roda; sentam no chão, em círculo e começam a leitura. Todos ouvem com atenção e depois conversam a respeito do texto. Ao término da leitura, os alunos, já em suas carteiras, começam a responder as atividades no livro didático. Partindo da intepretação do texto, eles produzem seus próprios textos, apresentando seus argumentos.

É importante ressaltar que os livros didáticos trazem atividades diversificadas de acordo com os níveis de ensino: $1^{\circ}, 2^{\circ}$ e $3^{\circ}$ ano e, assim, sucessivamente. Salienta-se que todos os alunos possuem livros didáticos específicos para cada ano, com exceção das crianças da pré-escola. Existem também os livros paradidáticos. O livro didático é um recurso muito presente na prática dessas professoras - são utilizados, cotidianamente, os de Língua Portuguesa e Matemática.

Contudo, apesar de darem ênfase a estas disciplinas, as professoras afirmaram que trabalham também as demais (História, Geografia e Ciências), pois afirmam serem também importantes para a aprendizagem dos alunos. Segundo Cavalcanti (2007, p. 131), “os livros didáticos e outros materiais de apoio ao professor, em princípio, têm uma proposta de temas a serem trabalhados de modo articulado e sequencial, em cada um dos anos escolares". Nessa ótica, os livros didáticos devem ser utilizados como suporte ao trabalho docente, devendo ter um vínculo com a proposta do professor; não sendo, porém, recomendável segui-lo à risca como material unilateral, ou definidor, do trabalho a ser realizado. 
Em algumas dessas escolas observadas, constatamos que os pais, ao deixarem seus filhos na escola, geralmente, entram no ambiente escolar, conversam com a professora e sentam seus filhos nas cadeiras. Os primeiros alunos que iam chegando, acomodavam-se em suas carteiras e aguardavam os demais colegas.

Assim, conversando, as crianças da pré-escola ficavam manuseando um brinquedo que traziam na sua bolsa. Como sabemos, a Educação Infantil tem como principais elementos de sua proposta pedagógica, conforme a Diretrizes Curriculares Nacionais para a Educação Infantil (BRASIL, 2010), a brincadeira, a convivência e a interação com outras crianças. É por meio da interação que ocorre a socialização. As brincadeiras representam uma forma peculiar de as crianças expressarem-se e de interagirem com outras pessoas, no processo de construção do conhecimento.

Em relação à referida assertiva, Oliveira (2002, p. 160) se expressa do seguinte modo:

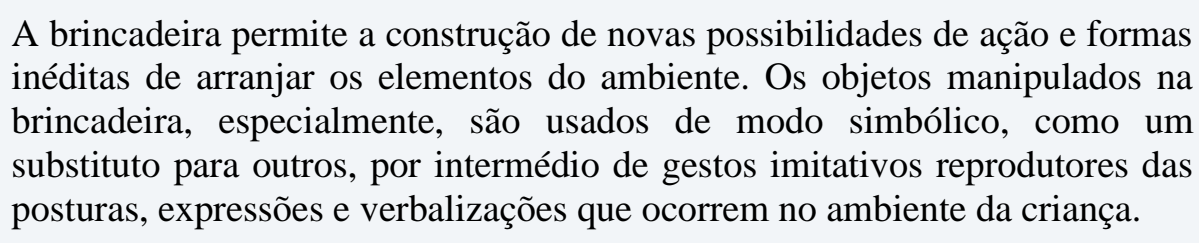

No que diz respeito às brincadeiras no espaço pesquisado, pudemos constatar que, por intermédio das brincadeiras livres, os alunos, de certa forma, interagem com o ambiente, por exemplo, ao brincar com pássaros e outros animais, bem como entre si.

Quanto às atividades para as crianças da pré-escola, todas as professoras reclamam por não terem livros específicos; sentem dificuldades de elaborar as atividades, já que as experiências que têm são com os anos iniciais. Diante disso, elas afirmam que é preciso escrever no caderno dessas crianças para que elas não fiquem apenas brincando, no decorrer das aulas.

Conforme Crepaldi (2006, p. 178), “cabe, portanto, ao educador não só acompanhar as atividades como promover oportunidades para a criança desenvolver-se, organizando espaços, disponibilizando objetos e materiais que possam enriquecer a brincadeira". Diante do exposto, e conforme relatos, as professoras investigadas não conseguem realizar um trabalho que atenda às peculiaridades das crianças da pré-escola. Além da pouca experiência com o referido nível de ensino, não há tempo disponível para atendê-las, o que prejudica o ensino dessas crianças.

Em seguida a professora P1 inicia sua aula dividindo o quadro por partes. De um lado, escreve o título da leitura, com letras cursivas, para os alunos do $3^{\circ}, 4^{\circ}$ e $5^{\circ}$ ano; do outro, com 
letras bastão ${ }^{1}$, para os alunos do $1^{\circ}$ e $2^{\circ}$ ano. Segundo essa professora, a aula é sempre iniciada com uma leitura referente à aula/tema que vai ser abordado; em seguida, continua lendo a História do gato Massamê e aquilo que ele vê. Nesse processo, os alunos ficaram concentrados, pois a professora pediu para prestarem atenção, uma vez que, posteriormente, iria fazer perguntas. Na sequência, questiona à turma: "vocês já viram um gato de óculos?". Os alunos responderam: "não!". A professora continua a leitura de forma lenta, imitando as personagens; em algum momento da história, interroga os alunos. Qual é o nome da história? Os alunos responderam: Gato Massamê e aquilo que ele vê. Falava do quê, a história? "Era um gato ou um tigre? Ele viu o quê?".

São várias as indagações e, nesse momento, os alunos responderam de acordo com a sua imaginação, pois os mesmos já haviam identificado o tipo de animal, não havendo mais necessidade de a professora colocar em dúvida sua compreensão. Concluída a leitura, pelo fato de haver apenas um exemplar, o livro foi repassado de carteira em carteira. O objetivo era para que todos pudessem manuseá-lo e visualizar o desenho para tirar suas próprias conclusões em relação ao animal que estava ilustrado na história.

Em seguida, um aluno mostrou o texto à professora, a mesma olhou e falou que faltava um ponto; e, dirigindo-se até à carteira de um aluno, falou: Pense numa aventura; você é capaz! Crie sua própria história. Nesse momento, observamos que a professora estimulou o aluno a criar sua própria narrativa, de acordo com o entendimento de cada um. Posteriormente, dirige-se às crianças da pré-escola e senta à pequena mesa para ajudar na realização de suas atividades.

Nesse momento, olha para a pesquisadora e fala que essa forma de trabalhar no coletivo facilita o trabalho nessas turmas e contribui à aprendizagem dos alunos. Assim, os alunos se ajudam entre si, já que os grupos são compostos por alunos que já sabem ler, junto aos que ainda não sabem. Porém as produções são feitas de forma individual. Ao concluir suas atividades, a professora $\mathrm{P} 1$ solicitou que os textos fossem apresentados aos colegas da turma; logo depois, os alunos expuseram para todos, que ficaram em silêncio, ouvindo as exposições.

Constatamos que todas as professoras explicitaram as dificuldades em trabalhar com as crianças da Educação Infantil, afirmando que, enquanto estão direcionando as atividades aos grupos de alunos dos diferentes anos, as crianças da pré-escola ficam aguardando sua vez, brincando ou até mesmo conversando com seus colegas.

\footnotetext{
${ }^{1}$ Letras escritas apenas na forma maiúsculas.
} 
Além dos cuidados na hora da alimentação, como também à ida ao banheiro ou até mesmo no acompanhamento nas brincadeiras, para as crianças não saírem machucadas, as professoras relatam também as dificuldades no que diz respeito à realização das atividades pedagógicas. Tal dificuldade, em larga medida, dá-se pelo fato de as docentes por não recebem orientações para trabalhar com essas crianças. Como sabemos, trabalhar em turmas multianos, juntamente com a educação infantil, requer uma metodologia diferenciada.

Conforme afirmaram todas as professoras, para trabalhar com crianças menores, ou seja, crianças da Educação Infantil, precisariam de um tempo disponível para atender às especificidades das mesmas, pois é preciso brincar com elas. Mas um brincar que tenha sentido, que seja direcionado ao desenvolvimento das crianças, e não algo aleatório. De fato, a criança é um ser ativo e criativo que, no decorrer de suas brincadeiras, expressa variadas formas de aprendizagem no cotidiano da escola, como também fora da instituição educacional.

Assim, verificamos, a partir das observações realizadas nas salas de aula, semelhanças e diferenças na prática das professoras, no que concerne aos conteúdos, metodologias e relação professor-aluno. $\mathrm{Na}$ verdade, cada professora trabalha conforme a sua experiência profissional e a partir da realidade dos alunos. Constatamos ainda, nas aulas das professoras P2 e P3, que ambas possuem uma prática diferenciada das professoras P1 e P4. Tal diferença relaciona-se ao fato de que estas últimas desenvolvem práticas que corroboram para que seus alunos tenham oportunidade de dialogar e questionar os conteúdos que são mediados, já que “o ensino deve ser dinâmico, variado” (LIBÂNEO, 2008, p. 107). Partindo desse pressuposto, presenciamos, nas aulas das professoras P1 e P4, que as mesmas se diferenciam, como por exemplo: realizam oficinas de leitura e de jogos pedagógicos.

É preciso que as atividades tenham significado para a aprendizagem dos alunos. Nesse sentido, a professora P1 utiliza jogos, tais como: dominó das letras; bloco lógico; jogos envolvendo quantidades; alfabeto móvel, dentre outros. Percebemos que a professora gosta de trabalhar com esse tipo de oficina, porque acredita que isso contribui para o processo de aprendizagem dos alunos. De acordo com essas metodologias, foi possível perceber os avanços, no sentido de que, nessas aulas, os alunos ficam mais estimulados. Mesmo sem suporte pedagógico, esta professora procura planejar aulas com base na especificidade dos alunos e, por esse motivo, sente-se satisfeita quando, no final do ano letivo, seus alunos estão lendo; o que ela apresenta como fruto de um trabalho árduo, mas gratificante. 
Sendo assim, compreendemos que o trabalho docente deve primar pelo conhecimento e pelas experiências sociais e culturais advindas da realidade dos alunos, para que os professores tenham clareza dos objetivos que devem trilhar rumo ao progresso dos alunos, no que tange as suas capacidades intelectuais.

\section{Educação do Campo em Pau dos Ferros: entre o real e o sonho, podemos pensar a construção do possível?}

Ao abordarmos a Educação do Campo, devemos ressaltar que é preciso acreditar que o campo é um lugar vivo, ou seja, um território social, econômico e político, no qual os sujeitos podem lutar de forma coletiva em prol de políticas públicas - sobretudo em relação à educação voltada à realidade dos povos campesinos. De acordo com Caldart (2004, p. 28), “A Educação do Campo precisa aprofundar a reflexão sobre como a escola pode ajudar a cultivar utopias e a formar militantes, respeitando a cultura camponesa e a própria fase da vida em que se encontram os diferentes educandos".

Desse modo, a escola do campo tem como finalidade desenvolver uma proposta de trabalho que seja capaz de redesenhar as práticas pedagógicas dos professores que atuam nessas escolas, no sentido de buscar conhecimentos para mediar o processo ensino aprendizagem dos educandos do campo. A Educação do Campo traduz a luta popular por uma escola pública de direito e de qualidade no campo, para os sujeitos que vivem nesse espaço, pois as pessoas precisam ser educadas no ambiente onde vivem. E ainda, segundo Souza (2012, p. 16) “A Educação do Campo nasceu dos pensamentos, desejos e interesses dos sujeitos do campo, que nas últimas décadas intensificaram suas lutas, espacializando-se e territorializando-se formando territórios concretos e imateriais”. A Educação do Campo busca fortalecer a identidade dos sujeitos que ali vivem.

Para Fernandes (1999, p. 65), "Uma escola do campo é a que defende os interesses, a política, a cultura e a economia da agricultura camponesa, que construa conhecimentos e tecnologia na direção do desenvolvimento social e econômico dessa população". Assim, pensar numa educação do campo é estar refletindo sobre as mudanças e os desafios que implicam essa modalidade de ensino.

Nessa perspectiva, ressalta-se que foi a partir da aplicação de entrevista que conhecemos a concepção dos sujeitos partícipes da pesquisa relacionada à Educação do Campo: professoras, gestora e supervisora escolar. Procuramos articular esse conhecimento com a nossa reflexão e análise acerca das informações e posicionamentos obtidos. Assim, fizemos aos sujeitos entrevistados o seguinte questionamento: O que você entende por 
Educação do Campo? Partindo de seus conhecimentos a respeito da temática abordada, os sujeitos responderam:

Assim, a Educação do Campo eu acho que é uma educação com especificidade, né? ela, ela é voltada pra essa realidade do homem do campo mesmo, né? É uma educação, eu, eu considero assim, especial, ela é específica, eu acho que é pra essa comunidade que realmente vive no campo, eu considero assim (Entrevista realizada com a P1, 2015).

(Pausa). (Risos). É uma educação que trabalha as necessidades, né? As exigências (pausa), do campo (pausa), de acordo com a (pausa), assim, com a necessidade de cada um, né? Com a cultura de cada um. Sua cultura, a cultura do campo (Entrevista realizada com a P2, 2015).

(Pausa), hoje né? É um estudo mais voltado pro campo, pra que as pessoas do campo continuem lá, né? Que venham pra cá, que vá pra outros lugares, que adquira mais conhecimentos, informação, mais que voltem, né? Pra lá $e$, e aplique seus conhecimentos lá, né $O$ que eu entendo é isso, que é a educação do campo é voltada pra isso, né? (Entrevista realizada com a P3, 2015).

(Pausa). É uma modalidade de ensino, né? Que tem como objetivo, assegurar os direitos dos, estudantes que vivem naquela localidade (Entrevista realizada com a SE, 2015).

(Pausa) A educação do campo eu vejo como um, um meio de (pausa), que realmente deve existir, educação do campo para que possa, aquelas pessoas, permanecerem aonde eles estão, né? Uma escola de, de qualidade. (Entrevista realizada com a GE, 2015).

A partir desses relatos, percebemos um distanciamento do embasamento teórico, no que diz respeito à concepção da temática abordada, isto é, a Educação do Campo. Tendo em vista que esta é fundamental para os sujeitos que vivem naquele local (os povos campesinos), a educação deve fazer parte de sua cultura, na busca da sua formação. Mas, conforme relato da professora P4, a Educação do Campo não pode ser relacionada à educação das escolas urbanas, pois ambas as perspectivas escolares divergem entre si, sobretudo em relação às propostas e perspectivas elaboradas, as quais têm por base o público a ser atendido.

Conforme Caldart (2004), a Educação do Campo além de se preocupar com a identidade cultural dos povos camponeses, ainda precisa resgatar o cerne da educação, no que tange aos valores humanos e sociais (emancipação, justiça, igualdade), como também o respeito à diversidade, buscando construir nas novas gerações, o valor da utopia e do engajamento pessoal, que conduz às causas coletivas humanas.

Partindo desse pressuposto, cabe relembrar ainda que a Educação do Campo está vinculada à dimensão histórica, social e cultural dos sujeitos que lá vivem. Assim, consoante 
os estudos acerca da concepção da Educação do Campo, bem como a sua relação com as classes multianos, fizemos o seguinte questionamento: qual a sua compreensão/entendimento acerca das classes multianos? Em suas respostas, obtivemos os relatos abaixo:

A minha compreensão, como é que eu entendo? (pausa) eu compreendo assim, que as classes multianos elas são, é um trabalho que é difícil de ser realizado, né?[...] Sente dificuldade de trabalhar com a Educação Infantil, com o ensino? Sim, a gente tem bastante dificuldade pra trabalhar com a pré escola porque são crianças que a gente tem que sentar com elas no chão contar história, pintar, recortar e a gente tem que atender aos demais e não dar pra suprir a necessidade, a dificuldade é essa, eu, eu considero porque eles precisam de atenção mais ainda e a gente tem que se desdobrar, é específico (Entrevista realizada com a P1, 2015).

(Pausa). É uma forma de aprendizagem diferente, porque, assim, um vai aprendendo com o outro (pausa). A gente vai ensinando para um, os outros vai se aperfeiçoando (pausa), aprender, né? (Pausa). Se ajudando. (Entrevista realizada com a P2, 2015).

É assim, porque todo mundo junto, né? Devido ser lá no campo, não tem essa possibilidade de ter professores, né? Às vezes é um só lá, que já tá lá, porque, dá zona urbana num vai pra lá, né Geralda? Ai a gente que, é a nossa realidade, temos que adaptar (Entrevista realizada com a P3, 2015).

(Pausa). Tem uma amiga minha que ela ri porque eu digo pra mim, é uma mistura que dá certo. Eu digo mulher é, (pausa), eu, eu trabalhei já com série multisseriado, com ano, agora pra mim, que eu me descobri professora no multianos [...] (Entrevista realizada com a P4, 2015).

Qual é a compreensão? A compreensão é que, a sala multianos, que hoje multianos com relação a essa nomenclatura que foi mudada, são as turmas (pausa), trabalhar com uma turma todo mundo junto, de primeiro ao quinto ano[...] (Entrevista realizada com a SE, 2015).

Classe multianos eu entendo porque eu também fui aluna da Educação do Campo, que eu nasci no campo, e sempre estudei, só que naquele tempo era multiseriada, né? Eu acho que (pausa) na realidade para o professor é, é difícil pra ele trabalhar, né? (Entrevista realizada com a GE, 2015).

Com base nas respostas das professoras, ficou evidente o quanto é difícil lecionar nas classes multianos, por se tratar de turmas de anos diferenciados e que, conforme as professoras P1, P2, P3 e P4, é preciso trabalhar formando grupos para facilitar o trabalho, como também proporcionar a aprendizagem dos alunos. Ainda constatamos o esforço das professoras ao estabelecer a interação com os alunos, visto que um aluno vai aprendendo com o outro, no decorrer das atividades. Nesse sentido, é prazeroso ver o modo como as crianças 
menores interagem com as maiores no decorrer das atividades, numa relação de respeito e sinceridade.

Ainda no que tange à Educação Infantil, questionamos a professora P1 a respeito do ensino com essas crianças, por tratar-se de uma turma na qual verificamos crianças de creche, ou seja, com idade inferior a quatro anos. $\mathrm{Na}$ fala da professora, percebemos ser um trabalho árduo, pois a educação destinada às crianças pequenas deve articular a integração entre os aspectos físicos, emocionais, afetivos, cognitivos e sociais.

É importante destacar que, mesmo diante às dificuldades enfrentadas pelas professoras no âmbito escolar, elas ainda conseguem alfabetizar mediante seus esforços e sua busca por metodologias, de seus saberes e experiências advindas da prática docente. Portanto,

Os professores têm muita dificuldade em organizar o processo pedagógico nas escolas multisseriadas justamente porque trabalham com a visão de junção de várias séries ao mesmo tempo e têm que elaborar tantos planos de ensino e estratégias de avaliação da aprendizagem diferenciados quanto forem as séries com as quais trabalham. (BARROS; MOURA, 2010, p. 2728).

Dessa forma, percebe-se que as professoras se sentem angustiadas, por terem que planejar atividades direcionadas, simultaneamente, para alunos que estão em vários níveis de aprendizagem.

Para Tardif (2002, p. 38-39), “os próprios professores, no exercício de suas funções e na prática de sua profissão, desenvolvem saberes específicos, baseados em seu trabalho cotidiano e no conhecimento de seu meio". Portanto, as docentes, no cotidiano, vão modificando sua metodologia de trabalho de acordo com a diversidade da turma, e adequando os conteúdos para que possam atender aos discentes em seu desenvolvimento.

Esses saberes são construídos, no decorrer dos anos de experiências, e acabam perfazendo itinerários de labuta intelectual na docência, cujos saberes tornam-se relevantes no exercício da profissão. Sobre isso, Tardif (2002, p. 239), nos fala que "os saberes dos professores se baseiam, em boa parte, em sua experiência na profissão e em suas próprias competências e habilidades individuais".

Assim, buscando aprofundar a questão do ensino nas escolas pesquisadas, e tendo em vista as discussões sobre a Educação do Campo, com foco no ensino nas classes multianos, apresentou-se aos sujeitos da pesquisa o seguinte questionamento: em sua opinião, quais os principais desafios ou dificuldades no ensino do campo em classes multianos? Os depoimentos, de modo sistematizado, revelam-se salutares à investigação ora apresentada: 
Vixe! As principais dificuldades (risos)! Falta de estrutura. Você acompanhando a gente, você viu a questão do planejamento como é, a gente quem se desdobra,[...]Assim, a gente se reúne com elas de quinze em quinze dias, às vezes passa vinte e dois dias, quando a gente chega lá, dão aqueles temas, a gente vai se desdobrar e pronto. Você viu como é, viu lá a gente, né? (Entrevista realizada com a P1, 2015).

(Pausa). Desafio é a estrutura pra escola, né? Espaço, na escola, né? Para que a gente fizesse um trabalho melhor. Como você viu, aqui não tem espaço. (Pausa) (Entrevista realizada com a P2, 2015).

(Pausa). A dificuldade que eu acho maior, é, é, as diferenças de idade, né? Porque você lidar com crianças com idades tão diferente. Eu acho isso muito difícil. Sei não! Tem gente que não acha, mas eu, eu acho. (Entrevista realizada com a P3, 2015).

É a falta de estrutura, é a falta de apoio, apoio pessoal (pausa). Assim, da gente ter uma pessoa, da gente ter uma criança com dificuldade e ter uma pessoa pra dar um reforço a essa criança. (Entrevista realizada com a P4, 2015).

(Pausa). Eu acho que seria, por exemplo: a falta de acompanhamento, que é um dos desafios. Eu acho que elas ainda não são atendidas como deveriam realmente de fato ser. (Entrevista realizada com a SE, 2015).

(Pausa) Os desafios eu acredito que é, como o aluno encontra assim, digamos nesse sentido, para o professor conseguir trabalhar com eles, [...] Precisa que ambos sejam, digamos assim, o professor, muito, muito preparado e também gostar daquilo que está fazendo, pra que o aluno possa, adquirir aqueles conhecimentos e, o aluno também ser muito atencioso. (Entrevista realizada com a GE, 2015).

As professoras assinalam como principais dificuldades para lecionarem nessas escolas: a ineficiência da estrutura física e a ausência do apoio pedagógico no cotidiano das atividades escolares, sendo esse último um dos fatores que dificultam ainda mais o trabalho docente. A escola do campo pode tornar-se mais educativa, de modo que ajude os sujeitos a perceberem o seu vínculo com as dimensões da vida humana, tais como: sua cultura, seus valores, suas posições políticas. Esta não precisa ser uma escola com aspectos agrícolas, mas uma escola direcionada à cultura dos sujeitos, a partir das relações sociais efetivadas no contexto em que estão inseridos.

Para compreendermos a ação pedagógica, em termos de subsídios para a efetivação das aulas, indagamos: a escola dispõe de recursos didáticos para serem trabalhados nas aulas? Caso possua, quais são estes recursos e como são utilizados?

Sim dispõe, dispõe de bastante livro, acervo literário (pausa) tem bastante, no cantinho de leitura tem muito livro. Temos o, a televisão com DVD que 
você tá vendo, né? Tem os jogos de alfabetizar, que tem aí o alfabeto, tem os jogos ali na sala, trabalhar de primeiro ao terceiro ano que eu também trabalho com quarto e quinto porque eles têm dificuldades de ler. (Entrevista realizada com a P1, 2015).

Recursos são esses, né? Mapas, globos, jogos, livros didáticos, dicionários, (pausa). São utilizados durante a aula, na sala de aula. (Entrevista realizada com a P2, 2015).

Dispõe, né? Os livros, os jogos, o que mais, meu Deus? (Pausa). Aquele material que você viu lá: jogos, livros, globo, mapas, essas coisas[...]? No plano de aula a gente já inclui, né? Faz a inclusão de como vai utilizar aquilo. (Entrevista realizada com a P3, 2015).

Sim. Jogos, silabário, mapas. A gente tem muito material, e a gente utiliza, de acordo com os nossos planejamentos. Eu gosto muito de trabalhar com eles, os jogos, os mapas, o globo. (Entrevista realizada com a P4, 2015).

$\mathrm{Na}$ fala das professoras, podemos constatar a existência de uma diversidade de recursos pedagógicos para serem utilizados nas aulas, os quais são: jogos das letras, silabário, dominó, mapas, jogos da trilha, os quais são utilizados de acordo com as aulas planejadas. De acordo com Freitas (2000, p. 21), “também conhecidos como 'recursos' ou 'tecnologias educacionais', os materiais e os equipamentos didáticos são todo e qualquer recurso utilizado em um procedimento de ensino, visando à estimulação do aluno e à sua aproximação do conteúdo".

Para Libâneo (2008), os materiais didáticos são os meios e recursos utilizados pelos docentes e pelos educandos para a organização e condução metódica no que se refere ao processo de ensino e aprendizagem. Porém, somente a professora P1 planeja uma aula especificamente para trabalhar com esses recursos, nos dias de sexta-feira. As demais utilizam, possivelmente sem tanta frequência, segundo o planejamento. Esses não são, contudo, os únicos recursos utilizados; já que o livro didático se configura, nessas escolas, como um dos recursos indispensáveis ao processo de aprendizagem dos alunos.

De fato, a sala de aula é o lugar privilegiado da prática docente, na qual ocorre uma relação de natureza pedagógica, mediante a transmissão dos saberes experienciais, advindos da carreira profissional, junto aos saberes da prática do cotidiano escolar. Considerando essa assertiva, procuramos compreender como as professoras se sentem em sua ação educativa, ao fazer o seguinte questionamento: como se sentem lecionando em salas multianos? Bem ( )

\section{Ruim ( ) Por quê?}

Bem, (pausa), bem, eu ia me, é. Quer que eu diga por quê? Eu me sinto bem, porque eu gosto do público, sabe? Eu me identifico com esse público, apesar das dificuldades, eu me identifico com eles, eu gosto, é um público mais 
diferenciado, [...]Eles são pouco mais recatados, eu acho que a educação é um pouco diferente a educação do campo que os pais dão em casa é mais diferente da rua da zona urbana, né? eu me identifico por isso, eu gosto. (Entrevista realizada com a P1, 2015).

(Pausa). Sinto bem, pela experiência que eu já tenho, né? (Pausa). (Entrevista realizada com a P2, 2015).

Não, eu já me sinto bem, porque já estou acostumada não tenho mais (pausa). Foi o cargo que me deixaram. Eu trabalhava (risos), só do pré ao primeiro ano, e de 2008 pra cá me colocaram pra uma sala de pré ao quinto ano e pronto, estou até hoje. (Entrevista realizada com a P3, 2015).

Bem (risos prolongados). Às vezes eu acho que não levo tão a sério. [...] Eu gosto de brincar, gosto muito de brincar. Mas eu trabalho bem, trabalho, me preocupo em trabalhar. Eu me preocupo em dizer pra eles o que eu acho. (Entrevista realizada com a P4, 2015).

Ao analisarmos as respostas das professoras, observamos uma unanimidade quando afirmaram que se sentem bem ao ensinar nas escolas pesquisadas, enfatizando que os alunos se comportam de forma diferente dos alunos das escolas urbanas. Vale destacar que, por serem turmas pouco numerosas, as professoras demostraram facilidade para socializar e mediar as atividades, por já possuir certa experiência adquirida no contexto da escola. Para a professora $\mathrm{P} 2$, essa realidade tem grande relevância na prática docente, pois a sala de aula é o lugar de interação. É neste espaço que acontece a troca de conhecimentos, em que professores e alunos se relacionam. Esse processo faz com que elas sintam prazer em lecionar, independentemente das dificuldades que permeiam o universo dessas escolas.

Dessa forma, a investigação mostrou, através da análise das entrevistas, um conhecimento acerca da prática docente nas escolas em estudo, bem como sobre o universo do ensino destes espaços de formação básica. Observamos, na mediação das ações pedagógicas, atitudes de respeito e interação com os educandos. Percebemos que, com a ajuda do professor, os alunos vão, paulatinamente, progredindo na formação de conceitos, de acordo com a sua criatividade e seguindo o desenvolvimento das suas capacidades cognitivas.

\section{Documentos oficiais: Regimento e Projeto Político Pedagógico das escolas com classes multianos}

No contexto escolar, sabemos que o Projeto Político Pedagógico possui um significado indiscutível, pois preocupa-se em estabelecer uma forma de organização do trabalho pedagógico, a fim de superar os conflitos existentes, e buscar romper com as rotinas individuais no ambiente escolar, propiciando uma vivência democrática na instituição. 
Assim, durante a análise do PPP, em 2015, uma versão ainda preliminar, pudemos verificar que o mesmo está sendo elaborado especificamente pelo Centro Municipal de Ensino do Campo, sem a participação dos segmentos escolares. Mesmo que as escolas estejam unidas ao Centro de Ensino, deveriam construir seu próprio Projeto Político Pedagógico, já que cada escola tem suas particularidades, e seu modo de planejar, de acordo com a diversidade existente em cada contexto escolar.

Segundo as professoras entrevistadas, o PPP não teve a participação coletiva, já que estava sendo elaborado pela gestora escolar do município. Diante dessa fala, constatamos que o PPP não está sendo elaborado de forma coletiva; o que se torna preocupante, pois esse documento deve ter a participação, além corpo docente, de toda a comunidade escolar. De acordo com Libâneo (2004, p. 151), “o projeto, portanto, orienta a prática de produzir uma realidade: conhece-se a realidade presente, reflete-se sobre ela e traçam-se as coordenadas para a construção de uma nova realidade, propondo-se as formas mais adequadas de atender necessidades sociais e individuais dos alunos".

Apesar de se tratar de um PPP, centralizado no Centro Municipal de Ensino do Campo no qual as escolas estão ligadas, e devido as suas peculiaridades, esse documento aborda as Diretrizes Operacionais da Educação Básica das escolas do Campo, elencando que essas escolas podem desenvolver algumas ações. Evidentemente que, dentre tais ações, destacam-se a aproximação do ensino com a realidade das crianças e a valorização dos saberes dos educandos do campo, tendo em vista as especificidades das escolas situadas no campo de Pau dos Ferros.

Conforme aponta Libâneo (2004, p. 153), “o projeto é um guia para a ação, prevê, dá uma direção política e pedagógica para o trabalho escolar, formula metas, institui procedimentos e instrumentos de ação". Partindo desse entendimento, percebemos que cada escola deve ter autonomia para construir seu PPP, e que esse trabalho deve ser realizado com o envolvimento da comunidade escolar.

A elaboração e execução do Projeto Político Pedagógico é o ponto de partida na açãoreflexão da prática docente. Portanto, o PPP, que está no início de sua elaboração, ou seja, encontra-se inconcluso, revela a ausência de vários pontos relevantes, dentre os quais, salienta-se o histórico das escolas. Desse modo, no decorrer de sua elaboração, é preciso repensar o ensino nessas escolas, bem como a valorização da identidade dos seus educandos, uma vez que o PPP precisa ter traços da Filosofia da Educação do Campo, ligados ao mundo da cultura e aos saberes dos educandos residentes no campo. 
Sobre o Regimento Escolar, trata-se de um documento, composto por artigos, parágrafos e incisos, o qual explicita/define todas as normas que regem a instituição escolar. Assim como o PPP, toda escola deve ter seu próprio Regimento, conforme a sua identidade. Porém, constatamos que esse documento é único para todas as escolas do campo pesquisadas, por se tratar de escolas que estão diretamente vinculadas ao Centro Municipal de Ensino do Campo.

Segundo o que está escrito no Regimento, averiguamos que esse documento está direcionado especificamente para o Centro de Ensino do Campo, e traz, nos seus artigos, elementos que são essenciais ao funcionamento escolar, como, por exemplo: matrícula, avaliação, ensino e aprendizagem, desempenho escolar dos alunos, entre outras normas que são relevantes ao processo educativo, nas instituições de ensino.

O Regimento, como o PPP dessas escolas deveriam ser elaborados por cada unidade escolar e atendendo às especificidades de cada escola localizada no campo, as quais funcionam apenas com turmas multianos, ou seja, turmas formadas por crianças da pré-escola ao $5^{\circ}$ ano do Ensino Fundamental, a saber: Unidade de Ensino XII Narcísia Amélia do Nascimento; Unidade de Ensino VIII José Alves Pereira; Unidade de Ensino XVIII Manoel Chagas de Aquino; e Unidade de Ensino V Francelino Granjeiro.

Isso posto, o capitulo $4^{\circ}$ do Regimento especifica que o diretor é único para direcionar, coordenar e organizar o Centro de Ensino, bem como as escolas que compõem esta instituição de gestão escolar. E, no título II, do artigo $2^{\circ}$, fica definido que o Centro Municipal de Ensino do Campo terá a finalidade de administrar, programar, supervisionar e coordenar as atividades nas Unidades de Ensino, mantidas pelo município, proporcionando aos educandos uma cultura geral básica, com a devida adaptação às Diretrizes da Educação do Campo.

Verificamos que o artigo $4^{\circ}$ destaca ainda que a gestão do Centro Municipal de Ensino do Campo deve ser conduzida por um único diretor, lotado na Secretaria Municipal de Ensino, o qual deve ter como finalidade organizar as atividades pertinentes a essas escolas, em conjunto com o corpo docente. Compreendemos que o Regimento Escolar, uma lei que rege todas as normas gerais da escola e que deve ser cumprido por todos os segmentos escolares, deve estar vinculado ao PPP. Por conta disso, toda escola precisa ter seu próprio Regimento para nortear as ações que ocorrem no âmbito do contexto escolar. Ademais, constatamos que esses são os únicos documentos encontrados, até o momento, no Centro Municipal de Ensino Campo, destinados às escolas com turmas multianos, nas quais foi realizada a pesquisa. 


\section{CONSIDERAÇÕES FINAIS}

Mediante o exposto, esta pesquisa nos possibilitou pensar, por meio da observação, como se realiza a prática docente nas classes multianos, lócus da nossa pesquisa. Constatamos, ainda, no relato das professoras, a dificuldade para lecionar nas classes multianos. Por se tratar de turmas de anos diferenciados, cabe ao professore procurar estratégias diferenciadas para proporcionar a aprendizagem dos alunos, sendo esses protagonistas na busca do saber. Dessa forma, o ensino nas classes multianos deve validar uma proposta que vislumbre a realidade, no que tange à diversidade dos povos do campo.

Acerca das discussões a respeito da escola do campo, outro ponto identificado diz respeito ao trabalho docente. Percebemos também que, nessas escolas, as professoras são comprometidas com sua prática, reinventando estratégias para conseguir alfabetizar os alunos da melhor forma possível. Por outro lado, existem alunos que são criativos, capazes, protagonistas e sujeitos, de modo que o professor precisa criar apenas as situações para mobilizá-los. Essas circunstâncias foram comprovadas nas escolas investigadas.

Por meio das observações da prática docente e dos relatos das educadoras acerca do ensino nas classes multianos, pudemos perceber um bom relacionamento entre professor e aluno, bem como aluno-aluno. Esse fato demostra, no contexto escolar, portanto, formas significativas de aprendizagem a partir da interação nos trabalhos em grupos, no momento do intervalo e nas brincadeiras livres.

Em geral, é no cotidiano escolar que as professoras procuram organizar sua prática, mediante um determinado tempo vinculado às rotinas ocorridas na instituição, como também a partir da própria dinâmica que permeia a atividade educativa nas classes multianos. Tais elementos acabam constituindo um desafio às professoras, ao expor os conteúdos para todos os alunos, de forma simultânea; sendo preciso adaptá-los de acordo com o nível de aprendizagem dos mesmos, como também tornando-se fundamental esperar todos terminarem para prosseguir a aula. Ao observamos a prática das professoras em exercício para as cincos turmas do ensino fundamental, em uma única sala de aula, além da presença de crianças de creche e pré-escola, notamos que lidar com tempos diferenciados de aprendizagem simultaneamente na mesma turma, representa um grande desafio à prática docente.

Enfatizamos, ainda, o fato dessas professoras lecionarem para as crianças da Educação Infantil, dificulta ainda mais o trabalho docente. Dentre as dificuldades, tal dificuldade recai no fato de as crianças pequenas necessitarem de atenção e cuidados específicos, que são 
fundamentais para seu desenvolvimento social e cultural. Além disso, a ausência do apoio pedagógico, no cotidiano das atividades escolares, dificulta ainda mais o trabalho docente.

Diante desse contexto, a pesquisa nos proporcionou um olhar mais aguçado a respeito da prática docente nas classes multianos. Apesar dos entraves existentes nesses espaços escolares, é possível verificarmos alunos alfabetizados e aptos para prosseguirem os estudos. Em síntese, os registros e análises advindos da pesquisa empírica trouxeram elementos que comprovaram os aspectos de uma realidade da prática docente nas classes multianos. Tais aspectos revelam os desafios enfrentados pelas professoras no ambiente escolar.

Dessa forma, faz-se necessário apontar caminhos para redimensionar a prática pedagógica nessa modalidade de ensino, o que sugere a necessidade de novos estudos que possam contribuir à melhoria da prática docente, com o intuito de colaborar com a aprendizagem dos educandos do campo.

Por fim, esse trabalho nos evidenciou a necessidade de aprofundarmos nossas reflexões acerca da prática pedagógica nas classes multianos nas escolas investigadas, numa perspectiva de ação-reflexão-ação. Deve-se considerar, para tanto, o respeito e a diversidade existentes entre os sujeitos que perfazem o espaço escolar, bem como os aspectos que permeiam a Educação do Campo, tais como a prática docente no ensino multiano.

\section{REFERÊNCIAS}

ANGOTTI, Maristela (Org.). Educação nfantil: para que, para quem e por quê? Campinas: Editora Alínea, 2006.

ARROYO, Miguel Gonzalez; FERNANDES, Bernardo Mançano. A educação básica e o movimento social do campo. Coleção: Por uma educação básica do campo n. 2. Brasília, 1999.

ARROYO, Miguel Gonzalez; CALDART Roseli Salete; MOLINA, Monica Castagana. (Org.). Por uma educação do campo. 5. ed. Petrópolis, Rio de Janeiro: Editora Vozes. 2011. p. 7-18.

BRASIL. Ministério da Educação. Secretaria de Educação Básica. Diretrizes Curriculares Nacionais para a Educação Infantil. Brasília: MEC, SEB, 2010.

CAVALCANTI, Lana de Souza. O Ensino de geografia na escola. Campinas: Papirus, 2012. (Coleção Magistério: Formação e trabalho pedagógico).

CREPALDI, Roselene; Brincar de construir brinquedos. In: ANGOTTI, Maristela (org). Educação infantil: para que, para quem e por quê? Campinas, São Paulo: Editora Alínea, 2006. 
FLICK, Uwe. Uma introdução à pesquisa qualitativa. Trad. Sandra Nertz. 2. ed. Porto Alegre: Bookman, 2009.

FREIRE, Madalena. A paixão de conhecer o mundo. Rio de Janeiro: Paz e Terra, 2007.

FREIRE, Paulo. Pedagogia da autonomia: saberes necessários à prática educativa. 40 . reimpressão. São Paulo: Paz e Terra, 1996 (coleção Leitura).

FREITAS, Olga. Equipamentos e materiais didáticos. Universidade de Brasília, 2007.

GE. Entrevista. Pau dos Ferros. Rio Grande do Norte, 2015.

LIBÂNEO, José Carlos; Organização e gestão da escola. 5. ed. Goiânia, Alternativa, 2004.

LÜDKE, Menga; ANDRÉ, Marli E. D. A pesquisa em educação: abordagens qualitativas, 2. ed. São Paulo: EPU, 1986.

OLIVEIRA, Zilma de Moraes Ramos de; Educação Infantil: fundamentos e métodos. 7. ed. São Paulo: Cortez, 2011.

P1. Entrevista. Pau dos Ferros. Rio Grande do Norte, 2015.

P2. Entrevista. Pau dos Ferros. Rio Grande do Norte, 2015.

P3. Entrevista. Pau dos Ferros. Rio Grande do Norte, 2015.

P4. Entrevista. Pau dos Ferros. Rio Grande do Norte, 2015.

ROCHA, Maria Isabel Antunes. Prefácio. In: Infâncias do Campo, (Coleção Caminhos da Educação do Campo). Autêntica: Belo Horizonte, 2013. p. 9-11.

SANTOS, Fábio Josué Souza; MOURA, Terciana Vidal. Políticas educacionais, modernização pedagógica e racionalização do trabalho docente: problematizando as representações negativas sobre as classes multisseriadas. In: ROCHA, A. I. Maria; HAGE, M Salomão (orgs). Escola de direito: reinventando a escola multisseriada. Belo Horizonte: Autêntica, 2010. p.35-47.

SE. Entrevista. Pau dos Ferros. Rio Grande do Norte, 2015.

TARDIF, Maurice. Saberes docentes e formação profissional. Petrópolis. Rio de Janeiro: Vozes, 2002.

SOUZA, Maria Antonia de. Educação do campo: proposta e prática pedagógica do MST, 2. ed. Petrópolis: Vozes, 2012.

WAJSKOP, Gisela. Brincar na educação infantil: uma história que se repete. 9. ed. São Paulo: Cortez, 2012. 


\section{$\underline{\text { SOBRE O(A/S) AUTOR(A/S) }}$}

\section{Geralda Maria de Bem}

Mestra em Ensino pela Universidade do Estado do Rio Grande do Norte (UERN); Professora da Secretaria Municipal de Educação de Pau dos Ferros - Brasil; Pesquisadora e técnica do grupo de pesquisa: Núcleo de Estudos de Geografia Agrária e Regional - NuGAR-UERN. Email: geraldabem@hotmail.com.

iD https://orcid.org/0000-0001-8440-9687

\section{Cícero Nilton Moreira da Silva}

Doutor em Geografia pela Universidade Federal do Ceará (UFC); Professor da Universidade do Estado do Rio Grande do Norte - Brasil; Professor do Programa de Pós-graduação em Ensino (PPGE); Pesquisador do Núcleo de Estudos de Geografia Agrária e Regional (NuGAR). E-mail: ciceronilton@yahoo.com.br

(iD https://orcid.org/0000-0001-6773-7451 